\title{
NOTES ON THE STRUCTURE OF SHELL AND MEMBRANES OF THE HEN'S EGG; A STUDY WITH THE SCANNING ELECTRON MICROSCOPE
}

\author{
P.-C.-M. SIMONS and G. WIER'TZ \\ Central Institute for Poultry Research "Het Spelderholt ", Beekbergen, \\ The Netherlands (Director : Ir. P. UBBELs) \\ Laboratory of animal Physiology, Agricultural University, Wageningen, \\ The Netherlands (Director : Prof. A. M. Frens)
}

\section{IN'TRODUC'TION}

For more than roo years microscopic studies have been made of the structure of the avian egg-shell. In the egg envelop different layers can be discerned termed classically : inner and outer membrane, mammillary and spongy layer and cuticle. In more recent work we meet with the terms : inner and outer membrane, cone and palisade layer, surface crystal layer and true cuticle (TYLER, I965).

During transport and handling of eggs more than Io p. IOO may crack. This results in a very important economic loss. Not very much is known about the structural factors in the shell that have an influence on the resistance of the egg to breakage. More research on shell structure may therefore be useful. Our work (Simors and WiERTZ, I965; El-Boushy, Simons and WIERTZ, I968) in which we used the light microscope and studies with the aid of the electron microscope (Srmons and WiERTz, I963, I966, I968) may be seen as a contribution in this field. Efforts to examine the surface of fractures through the calcified part of the shell by replication technique were not completely successful because of difficulties in removing the replicas untorn from larger areas of the fracture surface. So we were very glad to get the opportunity, though only for one and a half days, to do some research with a scanning electron microscope. Without much preliminary preparation the surface structure of rather bulky specimens can be studied over a wide range of magnification with a large depth of focus and a high resolution (200 $\AA$ for the average specimens ; that is about 20 times as good as the resolution provided by an optical microscope). A focussed electron beam strikes the surface of the object in I ooo lines. The primary electrons of this beam bring about the emission of secondary electrons by the object. These secondary electrons together with a few backscattered primary elec- 
trons are received in a collector that contains an accelerating electrode, a scintillator, a light pipe and a photomultiplier tube. The image is built up on a cathode ray screen, the scanning beam of which is syncronously coupled to the scanning primary electron beam. Because of their raster-character, photographs of the cathode ray image cannot be magnified many times. As at the contours of any relief in the object fewer secondary electrons are trapped, these contours show in the image bright edges (figs. 2 , $28,29)$. The egg shell is not a conductor. So it must be covered by a thin layer of conducting material like carbon to prevent the accumulation of negative charges at its surface.

\section{MATERIAL AND METHODS}

Pieces from the waist of egg-shells were glued with Velpon, a cellulose-acetate glue, on to a round aluminium plate (diameter $\mathrm{I} \mathrm{cm}$ ) and covered with a carbon film by evaporating carbon in a vacuum chamber. They were examined in the Stereoscan electron microscope of the Institute for Medical Physics in Münster (Western Germany). Pictures were made with a primary voltage of $10 \mathrm{kV}$.

Radial and tangential ground sections were prepared by grinding and polishing one side of the specimen according to the method of JoNGERIUS and HEINTzBERGER (I963). However, because of unsatisfactorily polishing, left too many of the grinding scratches, the radial sections had to be discarded. The sections were etched by boiling for ro minutes in a ro $\mathrm{p}$. roo solution of sodium sulfide.

The technique used for separating the inner from the outer membrane is as follows : saw the cap off the egg at the pointed end. Empty the egg and rinse the interior of the shell several times. Make a hole at the blunt end through shell and outer membrane. Blow through this hole into the air chamber and the inner membrane will come off.

After soaking the shell for 60 minutes in 5 p. Ioo EDTA at pH 7.2 the true cuticle with most of the pore plaques can be removed from the shell by washing the egg surface with a jet of water. Part of the calcite of the surface crystal layer will also be removed by this treatment which permits a view of the denuded surface of the calcified shell.

\section{RESULTS AND DISCUSSION (1)}

\section{True cuticle}

The description by SimONS and WIERTZ (I966) of the vesicular structure of the true cuticle with airspaces between the vesicles could be confirmed. The cuticular surface shows many star-shaped crack systems (fig. I). The big crack systems represent the surfaces of the oval pore plaques as suggested by SIMONS and WIERTZ (I966). The diameters of the surfaces of these plaques amount to over Ioo $\mu$. Their surfaces are flatter than the surrounding cuticular surface. The smaller crack systems elsewhere on the cuticular surface may be caused by a shrinking of the true cuticle directly after oviposition. Looking into a crack shows cuticular vesicles of up to about $\mathrm{I} \mu$ (fig. 2).

Simons and WIERTZ (I966) mentioned that with the passage of time the cuticular surface becomes increasingly flatter. The smaller crack systems then disappear gradually possibly due to a thinning of the true cuticle by the shrinking of the vesicles The cracks in the pore plaques on the other hand increase due to this shrinkage (fig. 3).

(1) Un diagramme représentatif de la section radiale de la coquille donné par les auteurs (Plate I) facilite la compréhension du texte. Note des éditeurs. 


\section{Denuded surface of the calcified shell}

The denuded surface of the shell, visible after removal of the true cuticle, shows pore holes and in some places the angular boundaries of the columns of the palisade layer may be seen with diameters of sometimes over $80 \mu$ (figs. 4 , 5). So at least part of the surface crystal layer has disappeared.

The pores are oval with diameters which can amount to more than $40 \mu$ (figs. 6, 7). Normally the upper part of a pore is filled up with a plug of cuticular material. Together with the true cuticle most of these plugs were removed. Figure 7 shows a pore in which part of this plug is still present. The wall of the pores is covered with a layer of organic material. Fibrils can be seen running parallel to the surface of the shells (fig. 8) at a distance of about $2 \mu$ apart. They may be the edges of the matted layers of fibrils seen in radial sections through the palisade layer (Simons and WIERTz, I963, fig. I3), which have the same relative distance.

\section{Shell fractures}

The scanning electron microscope is very useful for studying fractures through the shell. It is very interesting to see that fractures over the greater part of their length run along the organic matter. The only exception we met with is seen in figure 9 (left mammilla) and figure Io. This means that the strength of the organic matter will be an important factor in the breaking strength of the shell. This is in agreement with the positive relation between the compactness of the organic matrix in the palisade layer and shell strength mentioned by Simons and WIERTz (I963).

The cone layer composed of the so-called mammillae penetrates the outer membrane (figs. II, I2, I3, I4). The basal surface of the mammilla is smooth rounded off and covered with a thin layer of organic material (figs. 9, II, I2, I3, I4). This layer was also seen in radial sections (SIMONS and WIERTZ, I963, fig. Io).

Just beneath the base of the mammilla the outer membrane contains irregular calcified depositis through which fibres that penetrate the mammillary base pass in tufts (figs. II, I2, I3). Except at the spots where the fibres enter the mammilla there seems to be no contact between the mammilla and these calcified depositions (figs. I2, I3). They have been described earlier (e. g. Simons and WiERTz, I963; EL-Boushy, Simons and WiERTz, I968).

The only fracture through the calcified centre of a mammilla (figs. 9 to the left, Io) shows the cones, with maximum widths of $I_{5}$ and $30 \mu$, radiating from the crystallization centre of the mammilla. At the periphery of the cones the crystallites seem to be orientated nearly perpendicular to the cone surface. At the surface of transverse fractures through columns (figs. I6, I7) the same orientation is present (Compare the radial peripheral striations of crystal aggregates seen by HEYN, I963, fig. 6).

The organic coverings of neighbouring mammillary bases fuse between the mammillae and sometimes penetrate the shell for more than $7^{\circ} \mu$ (fig. II). Fractures follow these lines of least resistance (figs. II, I2, I3, I4). At many places entire cones are broken out of a mammilla, the fracture following again the thin layer of organic material between the cones (fig. II). Figures I4 and I5 show that after a Io $\mu$ wide zone, starting at the line of contact between two mammillae and rich in organic mate- 
rial, the quantity of this organic material between the mammillae decreases, the lamella-like crystallites becoming visible.

Everywhere in the calcified shell (figs. I5, I7, 20, 22) the organic matter contains many pitlike holes in which tiny crystals can be found (HEYN, I963). The highest magnification we used $(x 4200)$ does not yet permit a definite conclusion about their form, but vague diamond and hexagonal contours might point to rhombohedra. Figures 4 and 5 of HEYN (I963) give the same impression, though this author called them irregular. The greatest diameter of the pitlike holes in figure $I_{5}$ is $0.8 \mu$ and in figure $\mathrm{I} 7,0.5 \mu$. At the corresponding sites in radial sections they were seen as vesicles of $0.8 \mu$ and $0.4 \mu$ diameter (SIMONS and WIERTZ, I963). In the palisade layer a larger hole was seen (fig. $20,3.5 \mu$ ). In sections of egg shells from climate-stressed hens EL-Boushy, Simons and WiER'TZ (Ig68) found holes with diameters of 3.I, 5.8 and $9 \mu$. Indeed in ground sections through these shells much larger cavities were present.

In the palisade layer the plane of fractures may deviate from the strictly radial direction characteristic of the cone layer. Here and there transverse breaks through columns of about $5^{\circ} \mu$ diameter are present (figs. II, I6, I7) so that here the fracture runs in a tangential plane, parallel to the surface of the shell. But here again the fracture follows thin layers of organic material (matted fibrils with attached vesicles) which are seen to lie at relative distances of about $2 \mu$ through the whole of the palisade layer (SIMONS and WIERTZ, I963). The tops of the rhombic crystals visible at the front side of the broken column in figure 16 give an indication of several of these potential fracture planes. These layers of organic material may be seen far more clearly in figure I9 at the right side a little below the middle of the photograph and in figure $2 \mathbf{I}$. The fact that these tangential layers of fibrils are missing in the cone layer, together with the greater amount of organic material between the cones as compared with that between the columns, may account for the strictly radial course of the fractures through the cone layer.

The surface crystal layer is deposited on top of the palisade layer (figs. 2I, 22). It is about $8 \mu$ thick and consists of small calcite crystals with their greatest dimension about perpendicular to the egg surface. SImons and WIERTZ (I963) observed it in radial sections as a $1.5^{-2} \mu$ wide zone, predominantly fibrillar in structure. In ground sections examined in polarized light it varied in thickness between 3 and $8 \mu$. The deposition of this layer signifies the end of the formation of the calcified shell.

\section{Ground sections etched with sodium sulfide}

Figures 23 and 24 are photographs of an etched tangential ground section through the palisade layer. The irregular lines of organic material between the crystal aggregates are visible. Clearly seen too, are systems of parallel lines, running in four directions and enclosing rectangles and diamonds. These forms might be expected if the grinding plane intersects with rhombohedra. Neighbouring aggregates show line systems of different direction. In the palisade layer crystallites can be seen of $0.7 \times I \mu$ (figs. 20, 24).

\section{Membranes}

The inner membrane was separated from the outer one and photographs were taken from the plane of separation in inward and outward direction (figs. 25, 26). 
The inner membrane is much denser than the outer one. The thickness of the fibres in both membranes corresponds with the measurements in sections (SrMoNs and WIERTZ, I963). The average fibre diameter in the inner membrane is less than that in the outer membrane. In both membranes fibres often fuse. In the outer membrane composite bundles are seen of up to 4 fibres (fig. 26). The 4 -fibre bundle can be followed for more than $\mathrm{I} \mathrm{mm}$. There are not many broken fibres at the separation surface. The course of the fibres in the membranes shows some orientation. The thicker fibres run roughly parallel in systems forming diamond meshes. Yet there is some indication of a predominant direction, which might account for directional differences in strength of the membranes within the tangential plane and for the fact that the membranes may be torn from the shell in spiral strips. Schmint (I957) found that the membrane fibres take a spiral course around the egg axis.

On the outer surface of the fibres crystals may be seen of about $0.5 \mu$ length; at one place $\mathrm{I} 2$ crystals over a distance of $8 \mu$ can be seen. They may be hexagonal or rhombohedrial in form (fig. 27).

\section{Inner layer of inner membrane}

This flat layer (fig. 28) has already been described by SIMONS and WIERTZ (I963). In it granules with diameter of up to I $\mu$ can be seen, lying in short rows of roughly one direction (figs. 28,29 ). The layer shows small cracks (probably caused by shrinkage), some of which run in the same direction as the rows of granules.

\section{Shell of a boiled egg}

In a preliminary test of the apparatus, pieces of shell from a boiled egg were examined. The greater part of the membranes had been removed. The tufts of membrane fibres entering the mammillae as well as the calcified depositions around the fibres at these spots can be seen in figures 30 and $3 \mathrm{I}$ which are taken from the inside of the shell. In figure 30 the edge of the piece of shell lies a little below the top of the photograph.

Figure 32 depicts a radial fracture through some mammillae. Interesting too, are the two rhombohedrial crystals of 8 and $16 \mu$ diameter attached on the edge of a mammilla outside its organic covering.

The surface of the boiled cuticle is seen in figure 33. In it many rhombohedrial crystals of $2 \mu$ diameter are present. TYLER (I964) found calcium carbonate crystals in the outer cuticular layer of Anatidae eggs. Hevn ( 1963 ) described small cuticular bumps from underlying crystals. In his photograph their dimensions are about $0.2 \mu$. We have not previously met with crystals in the cuticle of hen's eggs.

\section{ACKNOWLEDGEMENTS}

The authors thank Prof. Dr. G. Pfefferkorn and Dr. R. Christenhuss of the Institute for Medical Physics of Münster University as well as Mr. S. Henstra of the Electron Microscopy Department of Service Institute for Applied Mechanics and Technical Physics at Wageningen who made this investigation possible. For the reproduction of the photographs thanks are due to Mr. C. VAN EDEN and Mr. C. I. VAN WIJK, Wageningen. 


\section{SUMMARY}

The structure of shell and membranes of the hen's egg was studied with a Stereoscan electron microscope. We examined cuticle, denuded surface of the calcified shell, radial fractures, etched tangential ground sections and membranes. Detailed descriptions and photographs are given. Fractures show a strictly radial course in the cone layer, but deviations to a tangential plane may occur locally in the palisade layer. In both cases the fracture mostly follows layers of organic material. The strəngth of the organic material in the shell may thus be an important factor in the breaking strength of the egg.

\section{RÉSUMÉ}

\section{ÉTUDE DE LA STRUCTURE DE IA COQUILI,E ETT DES MEMBRANES COQUILLIËRES DE I'GEUF DE POULE AU MOYEN DU MICROSCOPE, ÉLECTRONIQUE STÉRÉOSCAN}

La structure de la coquille et des membranes coquillières de l'ceuf de poule a été étudiée au microscope électronique Stéréoscan. Nous avons examiné la cuticule, la surface dénudée de la coquille calcifiée, des fractures radiales, des sections polies tangentielles gravées et les membranes. Des descriptions détaillées et des photographies sont présentées. Les fractures présentent dans la couche des cônes un trajet strictement radial mais des déviations vers le plan tangentiel interviennent localement dans la couche en palissade. Dans tous les cas la fracture suit le plus souvent des conches de matière organique. La solidité de la matière organique de la coquille peut par conséquent être une composante de la résistance à la rupture de l'œuf.

\section{REFERENCES}

E1-Boushy A. R., Simons P. C. M., Wiertz G., I968. Structure and ultrastructure of the hen's egg shell as influenced by environmental temperature, humidity and vitamin $\mathrm{C}$ additions. Poultry Sci., $47,456-467$.

HEYN A. N. J., I963. The crystalline structure of calcium carbonate in the avian egg shell. An electron microscope study. J. Ultrastructure Research, 8, I76-188.

Jongerius A., Heistzberger G., I963. The preparation of mammothized thin sections, Soil Survey Papers $n^{\circ}$ 1. The Soil survey Institute, Wageningen, the Netherlands.

Sснмidt W. J., I957. Ueber den Aufbau der Schale des Vogeleies nebst Bemerkungen über kalkige Eischalen anderer Tiere. Ber. Oberhess. Ges. Natur-u. Heilk. Giessen, Naturw. Abt., 28, 82-108.

Simons P. C. M., Wiertz G., I963. Notes on the structure of membranes and shell in the hen's egg. An electron microscopical study. Z. Zellforsch., 59, 555-567.

Simons P. C. M., Wiertz G., 1965. Differences in measurement of membrane thickness in hen's egg shells. Br. Poultry Sci., 6, $283-286$.

Simons P. C. M., Wiertz G., I 966 . The ultra-structure of the surface of the cuticle of the hen's egg in relation to egg-cleaning. Poultry, 45, II53-II62.

Simons P. C. M., Wiertz G., 1968. Notes on egg shell formation in the domestic hen. Lecture held at the 3rd European Poultry Conference $8-13$ sept. in Jerusalem, Israël.

Tyler C., 1964. A study of the egg shells of the Anatidae. Proc. zool. Soc., London, 142, 547583.

TYler C., 1965. A study of the egg shell of the Sphenisciformes. J. Zool., 147, I-I9. 


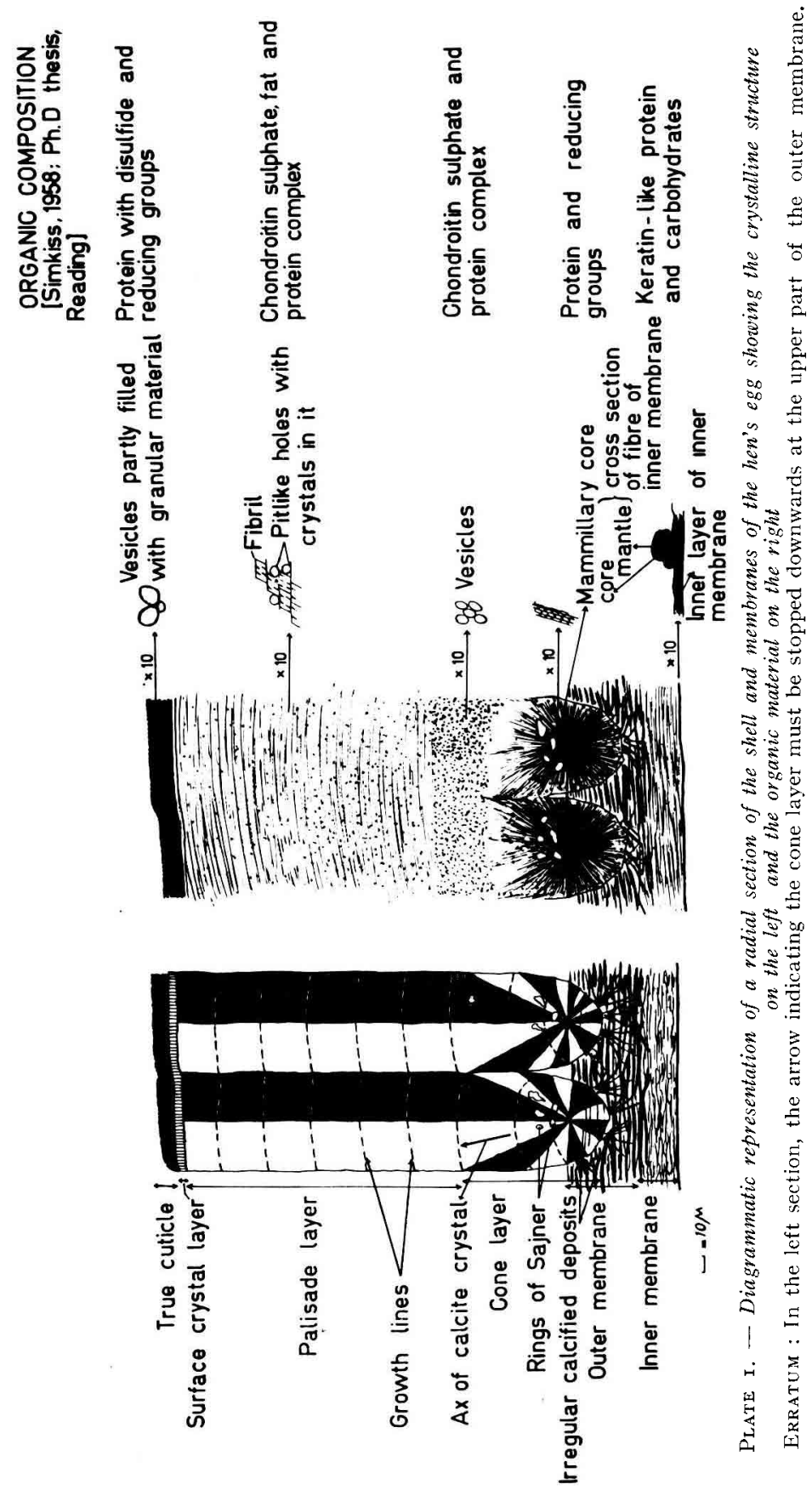




\section{PLATE I}

FIG. I

Cuticle of fresh egg. Pore plaque and surroundings. $273 \times$.

FIG. 2

Cuticle of fresh egg. Fracture in pore plaque. $260 \times$.

FIG. 3

Cuticle of old egg. $221 \times$.

FIG. 4

Shell surface, cuticle removed. $78 \times$.

FIG. 5

Shell surface, cuticle removed. $78 \times$.

FIG. 6

Shell surface, cuticle removed. Pore. $780 \times$. Detail of fig. 4 . 

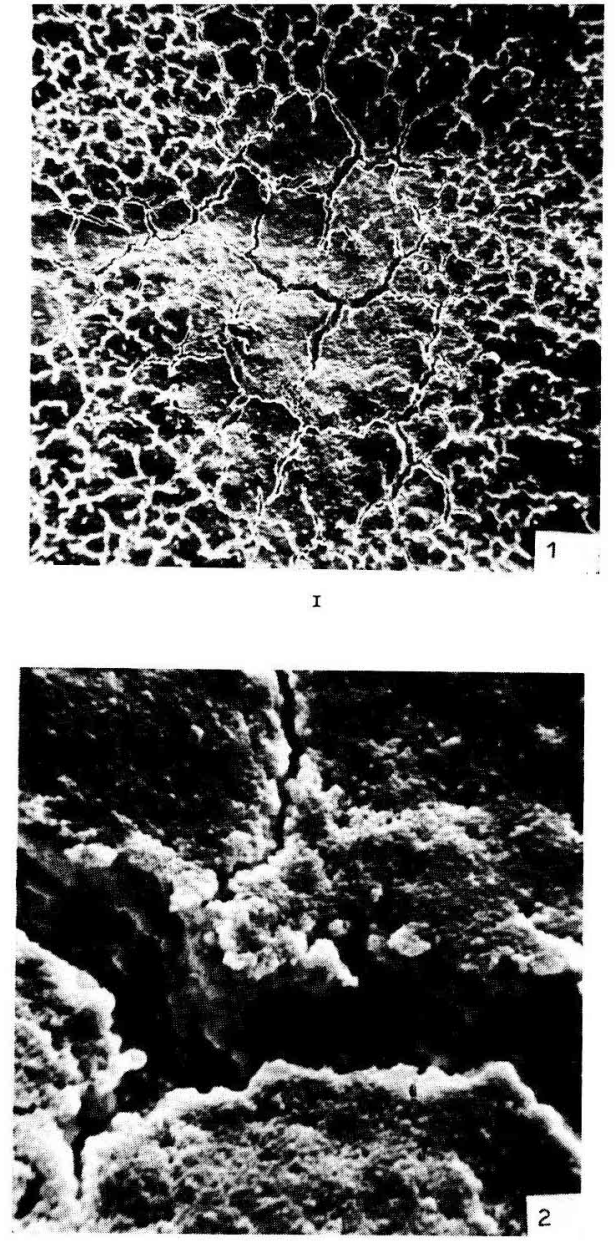

2

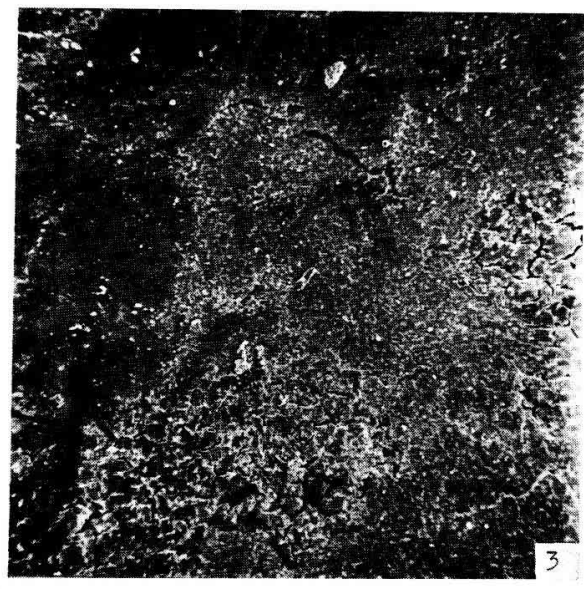

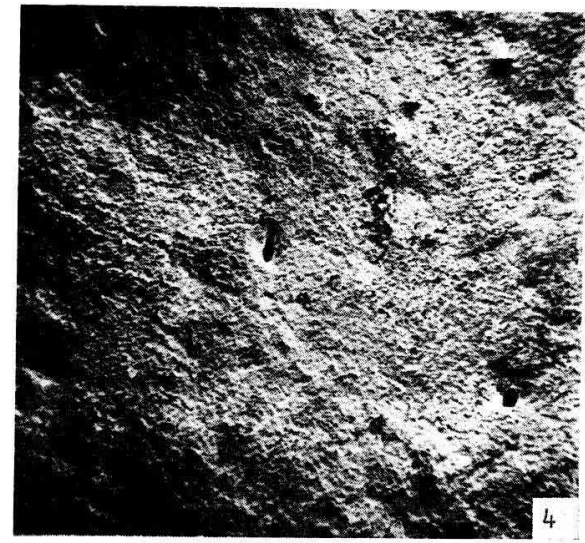

4

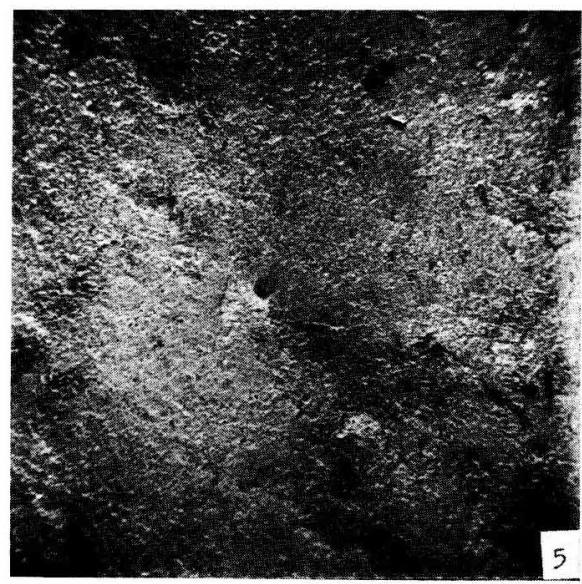

5

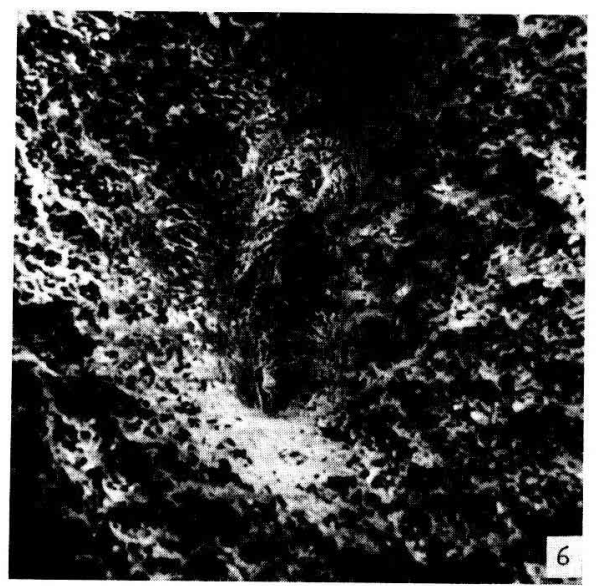

6 


\section{PIATE, II}

\section{FIG. 7}

Shell surface, cuticle removed. Pore $780 \times$. Detail of fig. 5 .

FIG. 8

Shell surface, cuticle removed. Pore wall. $234^{\circ} \times$. Detail of fig. 6 .

\section{FIG. 9}

Radial fracture surface. $260 \times$. Mammilla with fracture through centre.

FIG. IO

Radial fracture surface. $845 \times$. Fracture through centre of mammilla. Detail of fig. 9 .

FIG. II

Radial fracture surface. $273 \times$. Inner part of shell with part of membranes.

FIG. I2

Radial fracture surface. $9 \mathrm{I} \times$. Shell with membranes. 


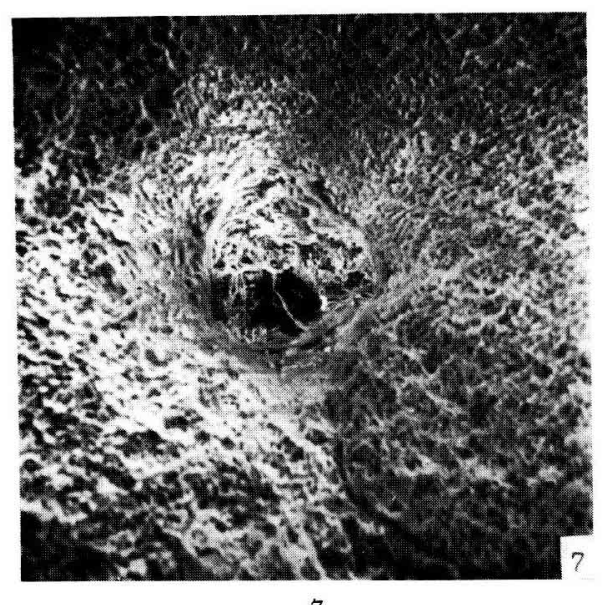

7

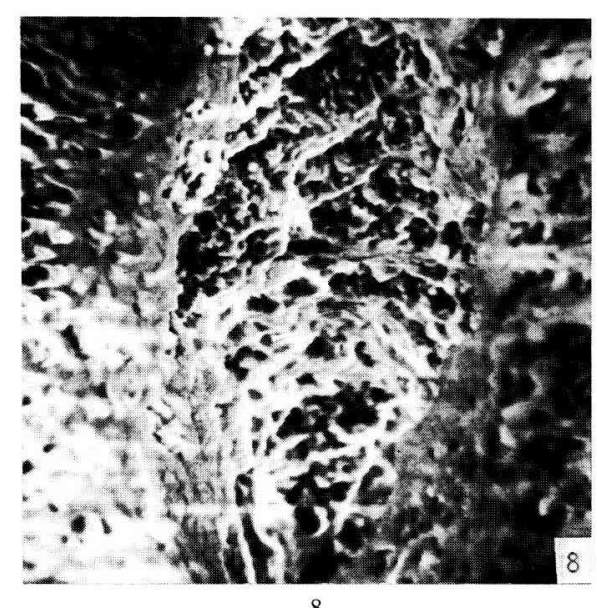

8

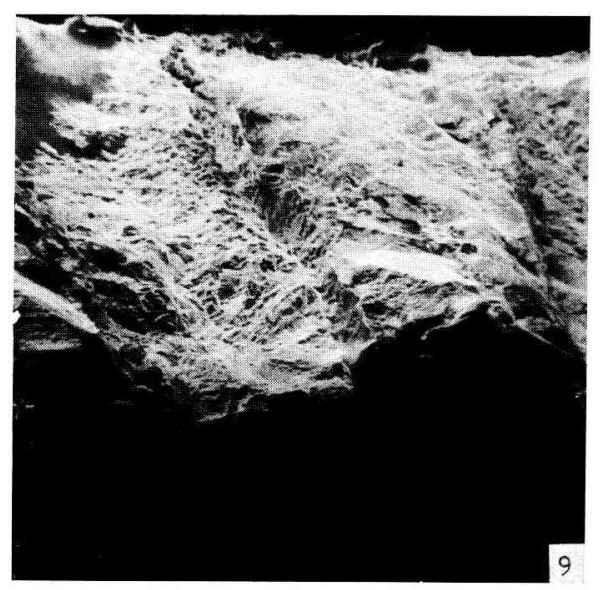

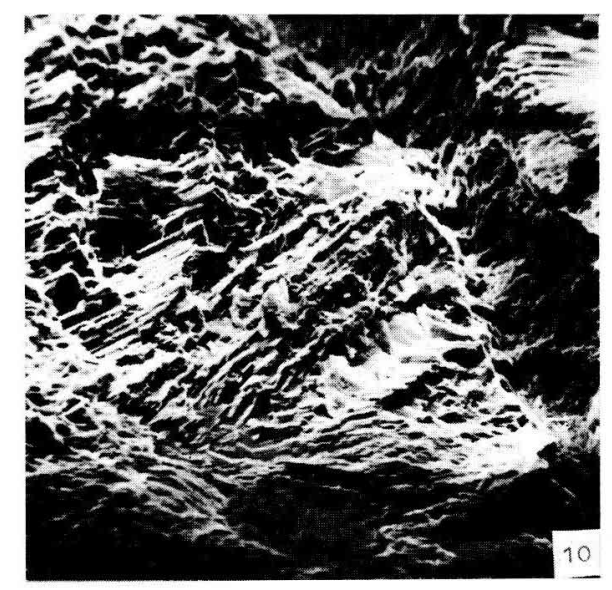

IO

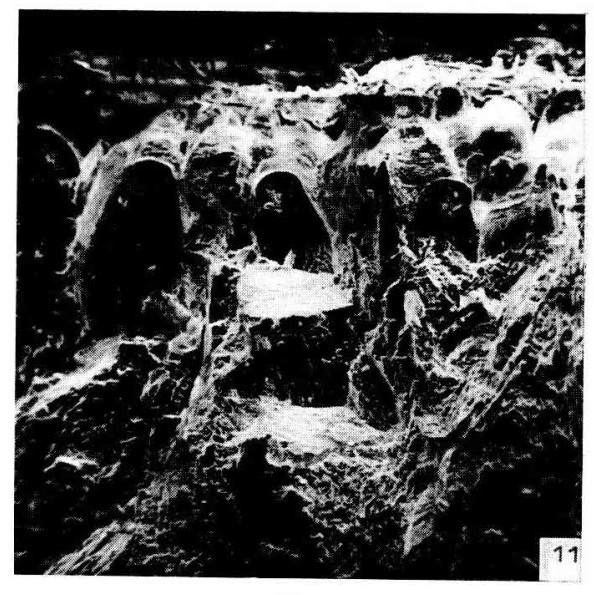

II

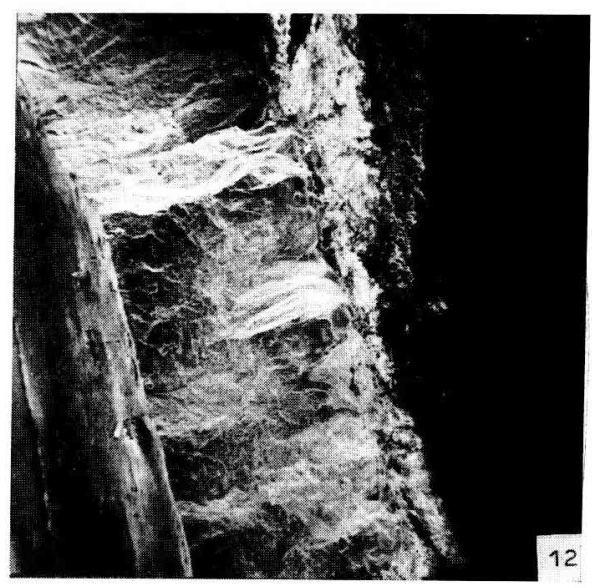

I 2 


\section{PLATE III}

FIG. I3

Radial fracture surface. $273 \times$. Mammillae and membranes. Detail of fig. I2.

\section{FIG. I4}

Radial fracture surface. 9 Io $\times$. Surface of mammillae. Detail of fig. I3.

FIG. I5

Radial fracture surface. $2730 \times$. Surface of a mammilla. Detail of fig. I4.

FIG. I6

Radial fracture surface. 9 Io $\times$. Fracture through column. Detail of fig. II.

\section{FIG. I7}

Radial fracture surface. $2730 \times$. Tangential fracture through column. Detail of fig. I6.

FIG. 18

Radial fracture surface. $273 \times$. Palisade Jayer. 


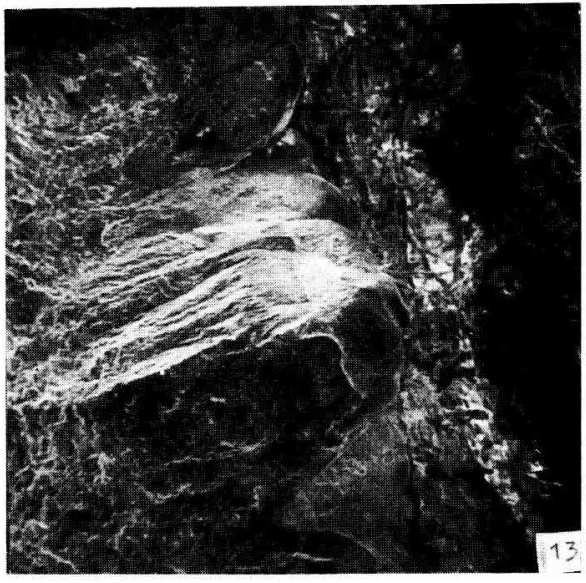

I3

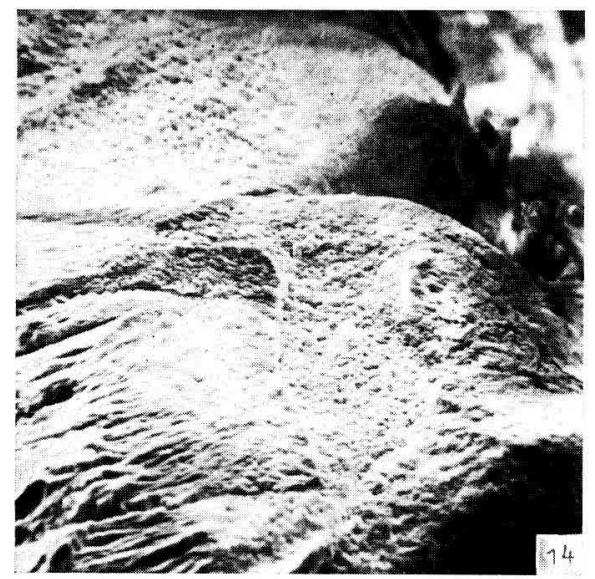

I4

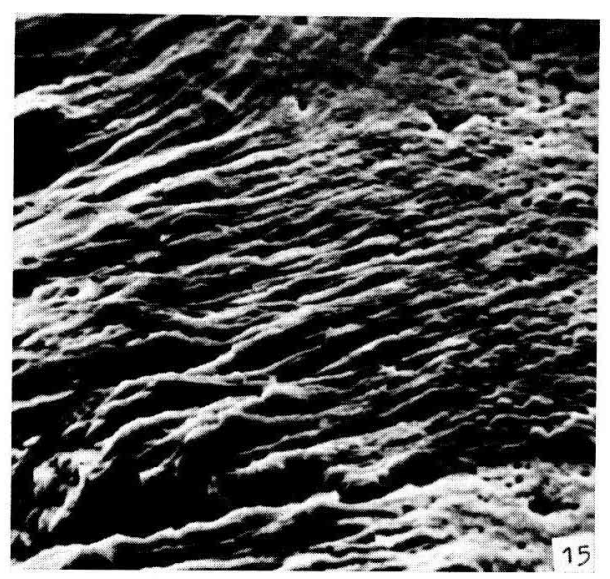

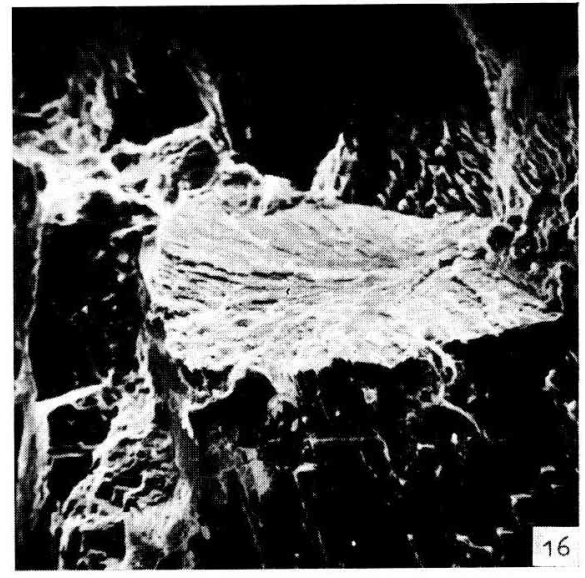

I6

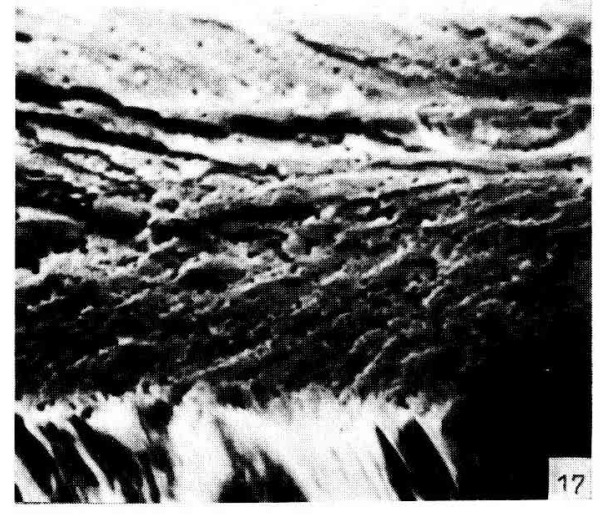

I7

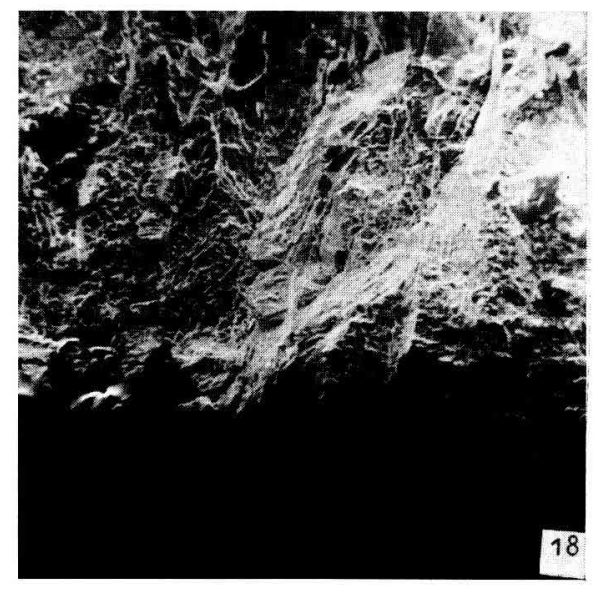




\section{PLATE IV}

FIG. I9

Radial fracture surface. 9ro $\times$. Palisade layer. Detail of fig. I8.

FIG. 20

Radial fracture surface. $273^{\circ} \times$. Palisade layer. Detail of fig. I9.

FIG. 2I

Radial fracture surface. $273 \times$. Inner part of shell. Detail of fig. I2.

FIG. 22

Radial fracture surface. $2730 \times$. Surface crystal layer. Detail of fig. 2 I.

$$
\text { FIG. } 23
$$

Etched tangential ground section. $234 \times$. Palisade layer.

$$
\text { FIG. } 24
$$

Etched tangential ground section. $2340 \times$. Detail of fig. 23 . 


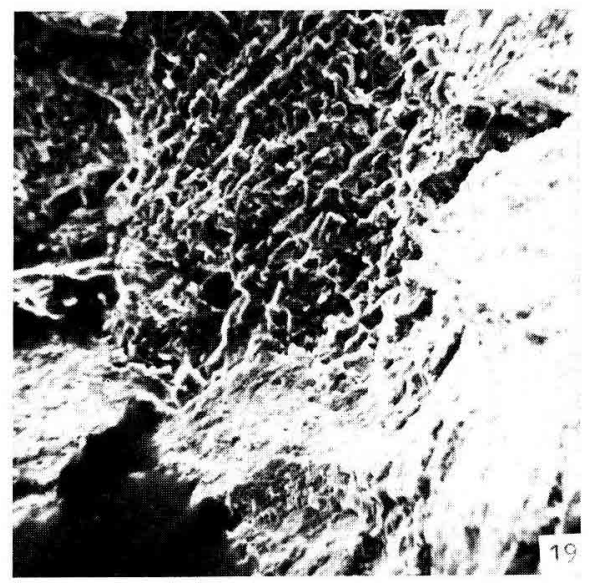

I9

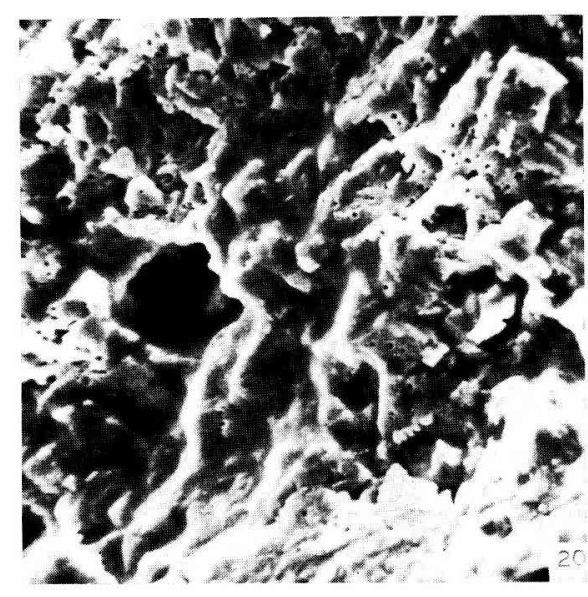

20

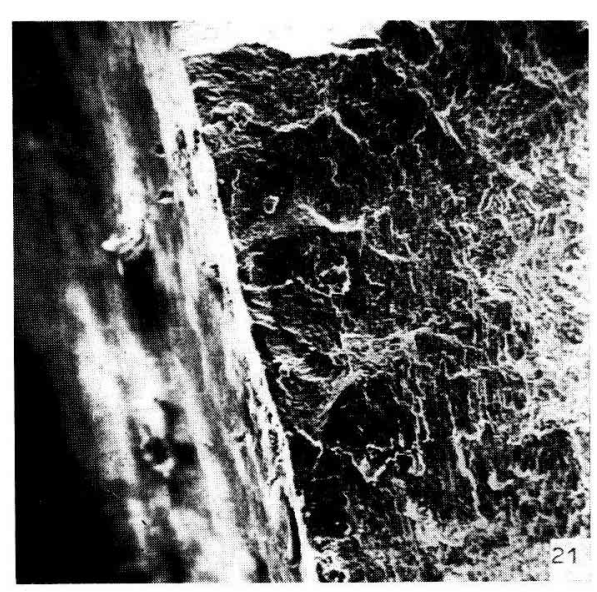

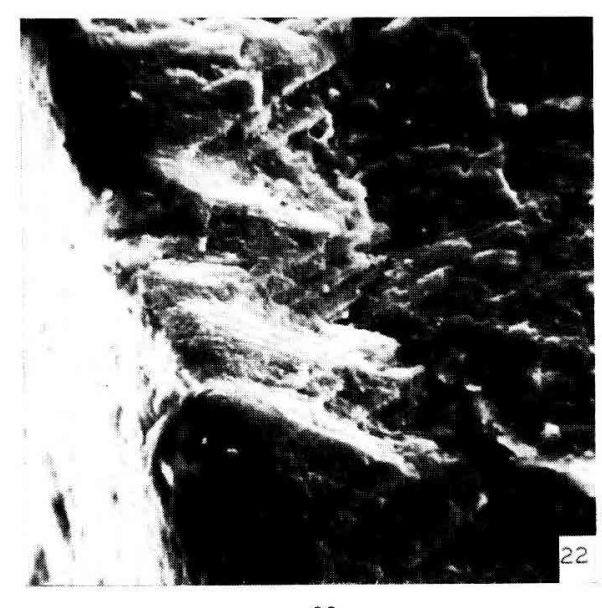

22

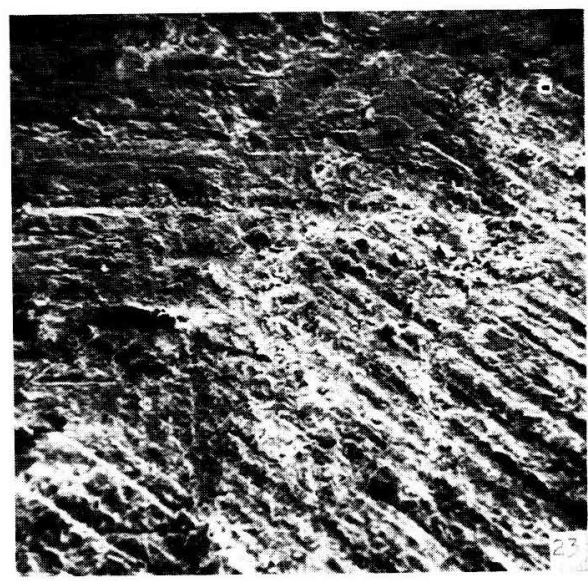

23

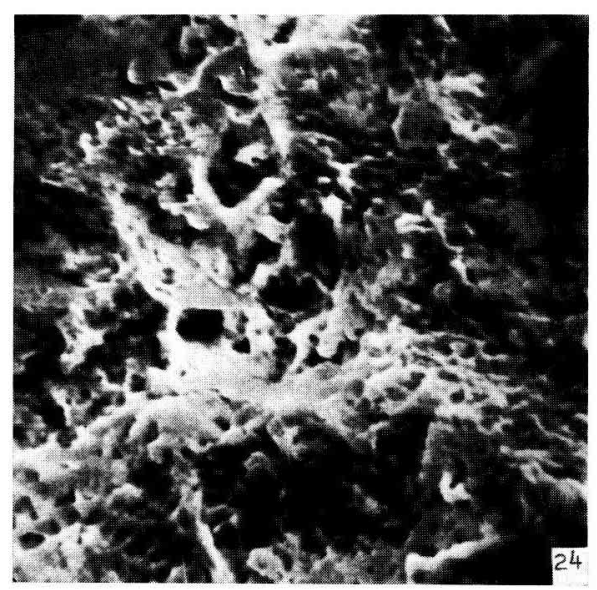


PLATE V.

FIG. 25

Inner membrane seen from outside. $747,50 \times$.

Fig. 26

Outer membrane seen from inside. $780 \times$.

Fig. 27

Outer membrane seen from inside. $2340 \times$. Detail of fig. 26 .

FIG. 28

Inner layer of inner membrane. $78 \times$.

FIG. 29

Inner layer of inner membrane. $234 x$. 


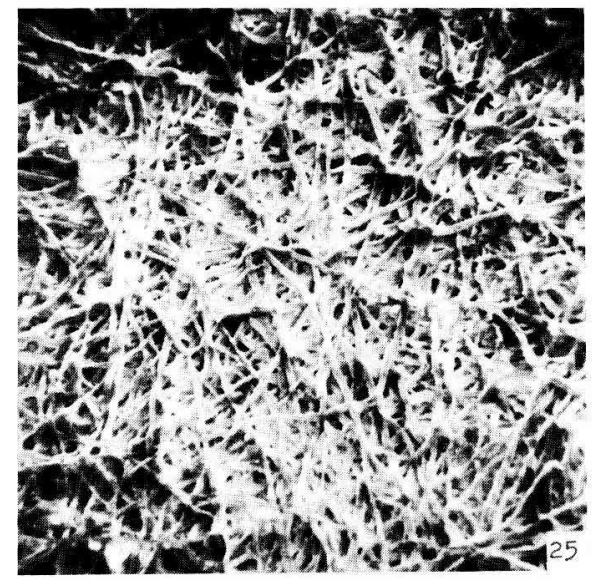

25

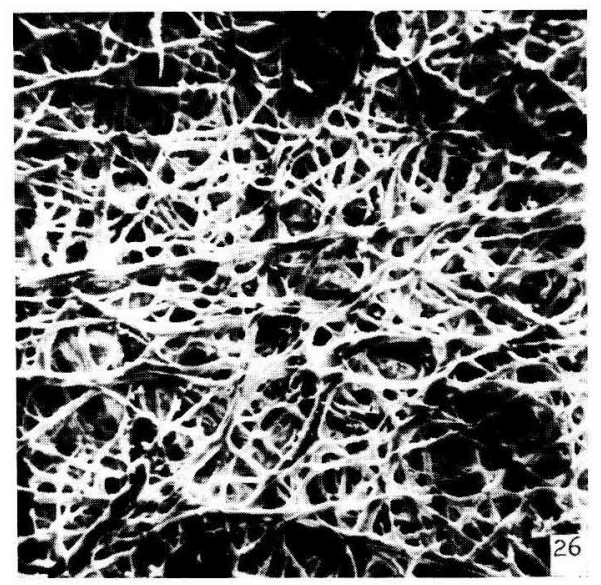

26

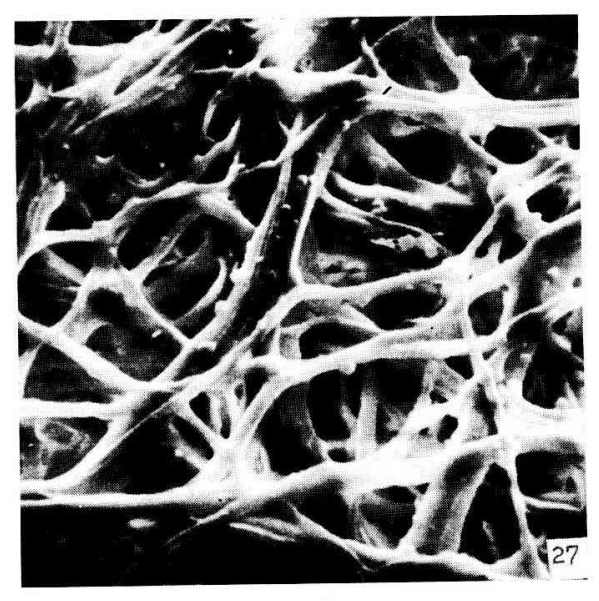

27

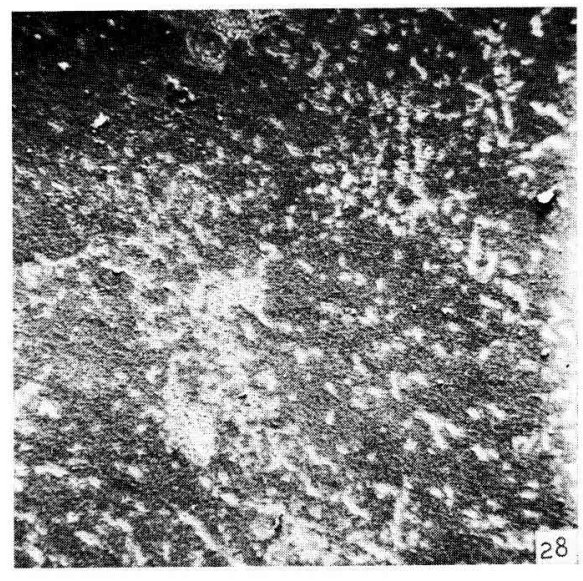

28

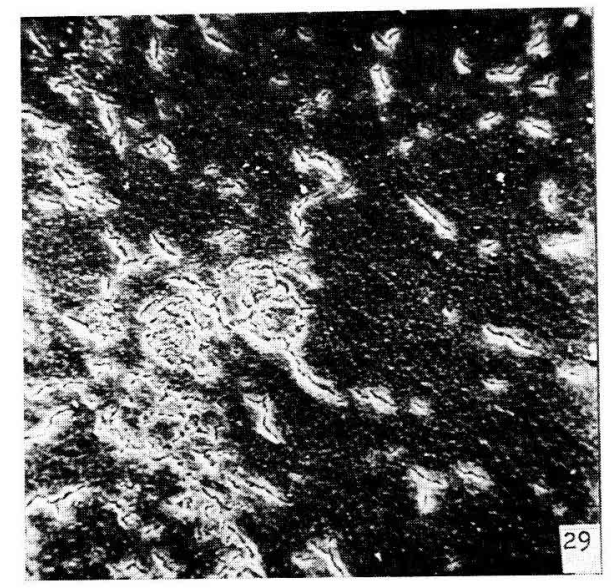




\section{PLATE VI}

Fig. 30

Boiled egg. Inside of shell. Membranes for greater part removed. 3 I2 $X$.

FIG. $3 I$

Detail of fig. 30 , I $040 *$.

FIG. $3^{2}$

Boiled egg. Fracture through shell. Mammillae. $260 \times$.

FIG. 33

Boiled egg. Cuticle. $2990 \times$. 

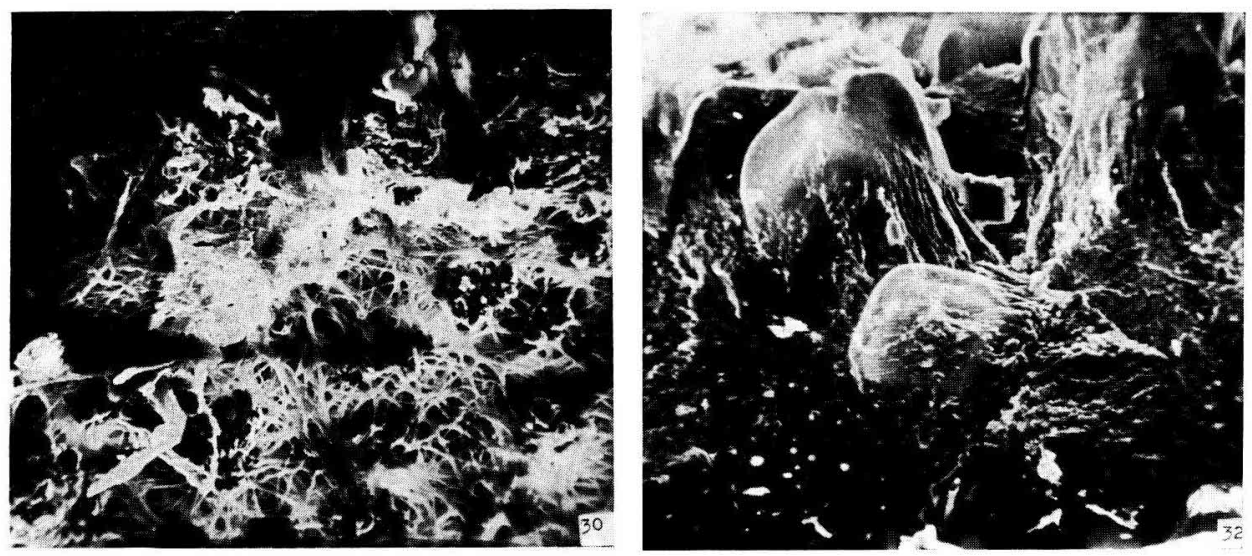

30

32

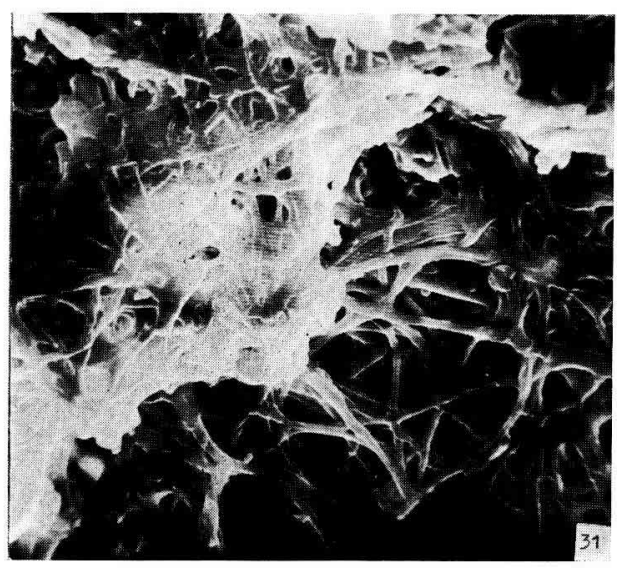

3I

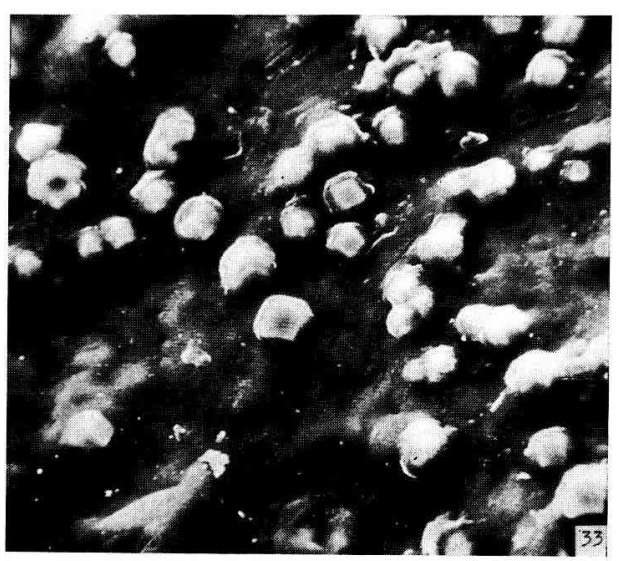

